\title{
A PILOT EXAMINATION OF DYADIC COPING INVENTORY AMONG JAPANESE MARRIED COUPLES
}

\author{
Kenji YOKOTANI ${ }^{1,2)}$ and Tai KUROSAWA ${ }^{3)}$ \\ 1) Niigata Seiryo University, Japan \\ 2) University of Zurich, Switzerland \\ ${ }^{3)}$ Ibaraki Christian University, Japan
}

\begin{abstract}
Couples cope with their stress as a unit rather than two isolated individuals. Couples coping were well examined by the Dyadic Coping Inventory (DCI) in European and American population, but not in Asian population. We aim to examine the applicability of DCI in Japanese married couples. Participants were 44 heterosexual couples in Japan. They answered the DCI and marital satisfaction. Results supported the applicability of DCI generally and showed several partner effects. The partner effects of DCI were discussed from the perspective of perceived social support.
\end{abstract}

Key words: couples coping, dyadic coping, Japanese, marital satisfaction

\section{INTRODUCTION}

People cope with their daily problems for themselves (Lazarus \& Folkman, 1984). However, in the context of couple relationships, people are motivated to cope with the problems not only for themselves, but also for their partners and relationships with the partners (Lyons, Mickelson, Sullivan, \& Coyne, 1998). Actually, when one partner distressed from his (her) cancer, many spouses utilized their own times to improve his (her) partners' distress (for a review, see Berg \& Upchurch, 2007). These coping behaviors have been defined as couples coping (CC). Research on CC was started by American (e.g., Coyne \& Smith, 1991) and European researchers (e.g., Bodenmann, 1995), so the findings of CC were mainly from European and American couples without a few exceptional studies (Falconier, 2013; Li \& Wickrama, 2014; Xu, Hilpert, Randall, Li, \& Bodenmann, in press). Hence, the generalizability of CC was limited within European and American population.

The present study was funded by Japan Society for the Promotion of Science (Grant-in-Aid for Young Scientists (B) [24792597]).

We appreciate all married and unmarried people for their participation. We also appreciate Prof. Guy Bodenmann for his comments on our early draft and Prof. Akiko Kawashima for her permission to use the Japanese-version Dyadic Coping Inventory.

We had no conflicts of interest with respect to the authorship or the publication of this article.

The authors assert that all procedures contributing to this work comply with the ethical standards of the relevant national and institutional committees on human experimentation and with the Helsinki Declaration of 1975 , as revised in 2008 .

Correspondence this article should be addressed to Kenji Yokotani, Graduate School of Clinical Psychology, Niigata Seiryo University, 1-5939, Suidocho, Chuo-ku, Niigata 951-8121, Japan (e-mail: yokotani@n-seiryo. ac.jp). 
To enhance the generalizability of CC, we sampled Japanese married couples and aimed to clarify the effects of CC in an Asian population.

\section{Dyadic Coping}

Daily distresses experienced by one spouse could be expressed directly or indirectly to the other partner in home so that the partner needs to cope with the spousal distressed expression regularly, regardless of whether the partner shares the distresses (Bodenmann, 2005). The spouse's coping behaviors affected the other partner's distress levels (Ditzen et al., 2007). Their partner's distress levels also affected the spouse's coping behaviors (Crossfield, Kinman, \& Jones, 2005). This circular relationship between daily distresses and daily coping in couples makes it easier to observe several CC patterns. Through observational studies, Bodenmann (1995) found positive and negative types of CC. The positive type of CC improved the couple relationships, but the negative one aggravated the relationships.

Bodenmann referred to several types of CC as dyadic coping (DC; 2005) and constructed Dyadic Coping Inventory (DCI; 2008). The DCI have been confirmed in Germany, Italian, French (Ledermann et al., 2010), Portuguese (Vedes, Nussbeck, Bodenmann, Lind, \& Ferreira, 2013), and Spanish (Falconier, 2013) speaking populations. The DCI has five categories of CC. Positive type of CC includes following four categories: Supportive DC occurs when one spouse assists the other through problem- and emotionfocused support (e.g., providing practical advice and expressing intimacy to the partner). Delegated DC refers to when one spouse takes over responsibilities to reduce the partners' distress (e.g., helping the partner's daily tasks). Joint DC is a process participated in simultaneously by both partners to handle stressful events (e.g., joint problem solving, relaxing together). Stress communication is constructive communication of one spouse's distress with the other partner (e.g., appreciating the partner's support). On the other hand, negative type of CC included Negative DC, which is superficial supportive behaviors that are accompanied by sarcasm and insincerity (e.g., supporting partner reluctantly).

The positive type of $\mathrm{CC}$ was correlated with marital satisfaction positively, whereas the negative type of CC was negatively (Bodenmann, 2005). These correlations were also found in longitudinal studies. For example, the husband's and wife's positive type of CC positively predicted his (and her) own marital quality among 110 Swiss heterosexual couples for 2 years, whereas the negative type of CC negatively predicted his (her) own marital quality (Bodenmann, Pihet, \& Kayser, 2006). Furthermore, these types of CC were used as an index of treatment studies. For instance, the 18-hour couple training that focused on enhancement of couples coping improved supportive and joint DC in Swiss couples, which were positively correlated with marital quality (Bodenmann \& Shantinath, 2004). Swiss couples who received this training demonstrated improved marital quality, communication, and intimacy after a year compared with those that did not receive the training (Bodenmann, Charvoz, Cina, \& Widmer, 2001). These accumulated findings suggest the links of $\mathrm{CC}$ with couple relationships. 


\section{Dyadic Coping in Japan}

One Japanese study found the links between DCI and couple relationships (Kawashima, Yoshitake, Matsumoto, \& Sugawara, 2014). Their online study found that the positive type of $\mathrm{CC}$ was linked with marital quality positively, whereas the negative type of CC linked negatively. This study suggested the applicability of DCI into Japanese couples with children, but the study did not include paired couple data. Even though distinction between intrapersonal effect (benefit for oneself) and interpersonal effect (benefit for spouse) is core for DCI (Bodenmann, 2005) and CC (Coyne \& Smith, 1991), previous Japanese study did not distinct these effects.

To overcome the limitation of previous Japanese DCI study, we sampled paired couple data and measured marital satisfaction (Schumm et al., 1986), which was popular to measure marital relationships. Furthermore, we also clarified intrapersonal coping effect and interpersonal coping effect through Actor Partner Interdependence Model (APIM). APIM clarifies actor's effects (e.g., wife's CC on her own marital satisfaction) and partner's effects (e.g., wife's CC on her husband's marital satisfaction) separately (Cook \& Kenny, 2005). The APIM for Japanese married couples could clarify effects of one's DCI both on one's own marital satisfaction and the one's partner's marital satisfaction separately.

The present study had two hypotheses regarding actor effects. First, the husband (wife)'s positive type of CC, including supportive DC, delegated DC, joint DC, and stress communication, would positively predict his (her) own marital satisfaction. Second, his (her) negative type of CC, including negative DC, would negatively predict his (her) own marital satisfaction. We also examined the partner effects of $\mathrm{CC}$ on these measures (e.g., effects of husband's supportive DC on wife's marital satisfaction) to clarify the interpersonal effects of CC.

\section{METHOD}

\section{Participants}

The 115 paired (230) questionnaires were distributed to Japanese married couples. The 106 questionnaires (46\%) were collected. Among the 106 respondents, 44 couples were identified. One set of paired data reported the same responses, including the other partner's gender, so this pair was excluded from the analysis. Final participants were 43 couples (43 wives and 43 husbands). Regarding location, 20, 14, 6, 2, and 1 couples lived in Tohoku (northeast), Kansai (west), Chubu (central), Kyushu (south), and Kanto (east), respectively. The mean ages of wives and husbands were $45.2(S D=14.5)$ and $46.1(S D=15.8)$ years, respectively. The mean marital duration was $18.2(S D=15.5)$ years. All couples had been married for at least one year (maximum: 55). Marital duration was not significantly correlated with subscales of DCI or marital satisfaction, though a correlation between marital duration and wives' stress communication reported by husbands was near significance $(r=-.29, p<.10)$. Hence, we did not include age and marital duration in the analyses.

\section{Procedure and Materials}

Two leaders of the local communities in Tohoku and Kansai recruited couples in their communities. Three university professors also recruited familiar couples in Chubu, Kyushu, and Tohoku. Couples who showed interest in participating received questionnaires in October, 2014. The questionnaire included separate and distinct materials for each partner, along with a return-mail envelope and instructions for returning questionnaires to the laboratory by the first week in November 2014. Anonymous participation did not allow us to write them receipts, so we did not pay for their participation. In addition to their basic information, we 


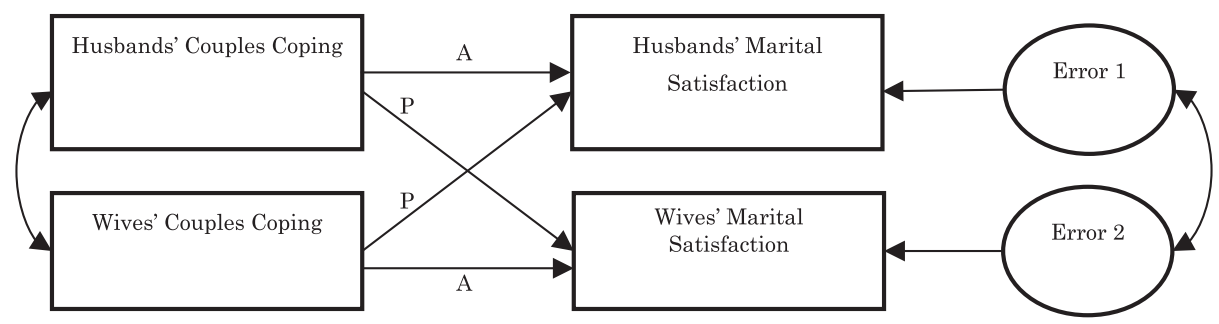

Fig. 1. Actor-partner interdependence model Note: A represents actor effect; P represents partner effect. Couples coping has five categories: Stress communication, supportive dyadic coping (DC), delegated DC, negative DC, and joint DC.

collected data on couples' coping, and marital satisfaction.

Couples coping. The DCI (Bodenmann, 2008) Japanese version (Kawashima et al., 2014) was used to measure comprehensive DC. The DCI is a 37-item questionnaire with responses indicated on a 5-point Likert type scale $(1=$ very rare to $5=$ very often $)$. Respondents evaluated their own DC, their partners' DC, and joint DC as a couple. The DCI has five categories with nine subscales: stress communication by oneself (items 1, 2, 3, and 4: "I tell my partner openly how I feel and that I would appreciate his or her support") and by the partner (items 16, 17, 18, and 19); supportive DC by oneself (items 20, 21, 23, 24, and 29: "I express to my partner that I am on his or her side") and by the partner (items 5, 6, 8, 9, and 13); delegated DC by oneself (items 28 and 30: "I take on things that my partner normally do in order to help him or her out") and by the partner (items 12 and 14); negative DC by oneself (items 22, 25, 26, and 27: "I make fun of my partner's stress") and by the partner (items 7, 10, 11, and 15); and joint DC (items 31, 32, 33, 34, and 35: "We help each other relax with such things like massage, taking a bath together, or listening to music"). The averages of these items were scored for each subscales. Like the French, Italian, German (Ledermann et al., 2010), and Portuguese (Vedes et al., 2013) versions, the Japanese DCI was back-translated and has shown good reliability, except for delegated DC (Kawashima et al., 2014).

Marital satisfaction. The Kansas Marital Satisfaction Scale (Schumm et al., 1986) Japanese version (Sugawara \& Takuma, 1997) was used. This scale consists of three items (e.g., "How satisfied are you with your marriage?"; "How satisfied are you with your husband/wife as a spouse?"; "How satisfied are you with your relationship with your husband/wife?") rated on a 7-point scale from 1 (extremely dissatisfied) to 7 (extremely satisfied). This scale has shown good reliability (Schumm et al., 1986) including Japanese couples (Sugawara \& Takuma, 1997).

Analyses

We used the APIM to simultaneously estimate the actor (e.g., husband's CC affects his own marital satisfaction) and partner (e.g., husband's CC affects his wife's marital satisfaction) effects of CC on couple marital satisfaction (Kenny, Kashy, \& Bolger, 1998; Cook \& Kenny, 2005). Application of this model is especially appropriate if the variables measured in both partners can be conceived of as common dyadic constructs. Using structural equation modeling, we tested our hypothesis with the maximum likelihood method. Our dependent variable was marital satisfaction only, whereas our independent variables were 5 CC categories (Fig. 1). Hence, we build 5 APIMs separetely. HAD version 15.005 (Shimizu, 2016) was used for analysis.

\section{RESULTS}

\section{Comparison of Dyadic Coping with European data}

Table 1 shows descriptive statistics of the nine DCI subscales, and marital satisfaction. Among these 24 scales, five (21\%) did not have satisfactory internal consistency $(\alpha<.70)$, 
PILOT EXAMINATION OF DCI

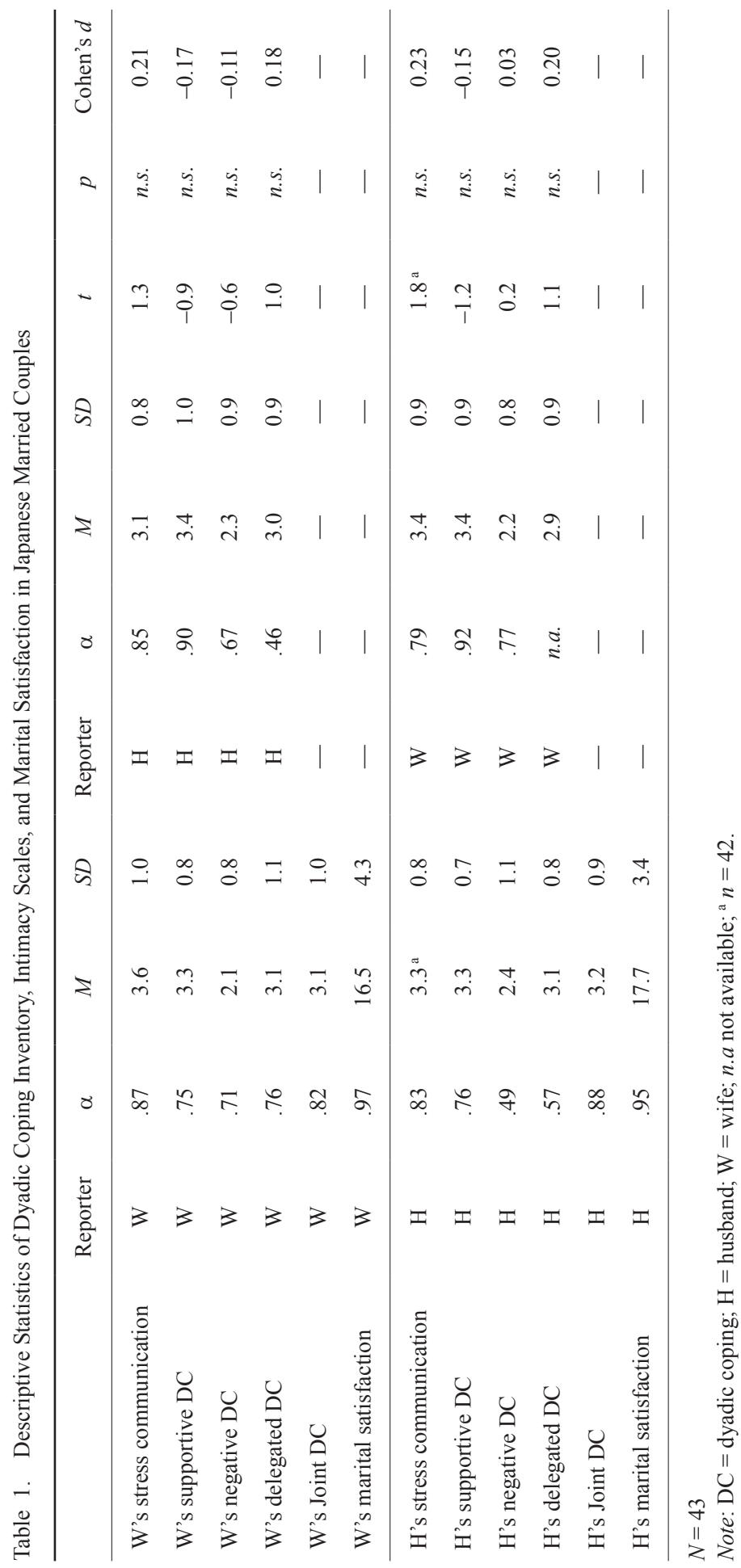


Table 2. Correlations for Wives and Husbands in Japanese Married Couples

\begin{tabular}{lllclll}
\hline & 1 & 2 & 3 & 4 & 5 & 6 \\
\hline 1. Stress communication & $.70^{\mathrm{a} * * *}$ & $.49^{\mathrm{a} * *}$ & $-.06^{\mathrm{a}}$ & $.46^{\mathrm{a} * *}$ & $.58^{\mathrm{a} * *}$ & $.53^{\mathrm{a} * *}$ \\
2. Supportive DC & .25 & .16 & -.11 & $.62^{* *}$ & $.60^{* *}$ & $.53^{* *}$ \\
3. Negative DC & -.23 & .20 & $.37^{+}$ & .23 & $-.28^{+}$ & -.22 \\
4. Delegated DC & .24 & $.37^{*}$ & $.32^{*}$ & $.47^{*}$ & $.40^{* *}$ & $.32^{*}$ \\
5. Joint DC & $.58^{* *}$ & $.48^{* *}$ & -.19 & $.26^{+}$ & $.73^{* * *}$ & $.46^{* *}$ \\
6. Marital Satisfaction & $.60^{* *}$ & .09 & $-.36^{*}$ & .09 & $.44^{* *}$ & $.52^{* *}$ \\
\hline
\end{tabular}

$N=43$

Note: Correlations for wives are on the lower diagonal, correlation for husbands are on the upper diagonal, and paired correlations (between wives and husbands) are on the diagonal. The paired correlations are intra-class correlations, whereas the other correlations are Pearson's correlations. $\mathrm{DC}=$ dyadic coping. ${ }^{\mathrm{a}} n=42$. ${ }^{* * *}: p$ $<.001, * *: p<.01, *: p<.05,+: p<.10$

but the other 19 scales $(79 \%)$ did $(\alpha>.70)$. In contrast to European data (Ledermann et al., 2010), alpha of husbands' delegated DC (.57) and negative DC (.49) in the present study were small (Swiss population; .86, .61, respectively).

Furthermore, supportive DC in our participants was significantly lower than European (Swiss) couples regardless of gender differences $(t=5.3, d f=49.9, p<.001$ for wives; $t=6.0, d f=52.4, p<.001$ for husbands). In the same line, negative DC in our participants was significantly higher than European (Swiss) couples regardless of gender differences ( $t=4.8, d f=48.7, p<.001$ for wives; $t=5.3, d f=45.5, p<.001$ for husbands).

Table 2 also shows intra-class correlations (ICCs) on the diagonal. ICCs of stress communication, negative DC, delegated DC, joint DC, and marital satisfaction were all over .45, and thus, these measures could be treated as paired data (Kenny et al., 1998). However, the coefficients for supportive DC and negative DC were under $.45^{1}$.

\section{Prediction of Dyadic Coping on marital satisfaction}

Table 3 shows 5 APIMs of DCI on marital satisfaction. As expected by hypothesis 1 , both husband's and wife's stress communication and joint DC positively predicted his (her) own marital satisfaction significantly. Although husband's supportive DC predicted his own marital satisfaction positively, wife's supportive DC did not predict her own marital satisfaction. As expected by hypothesis 2, wife's negative DC predicted her own marital satisfaction negatively, but husband's negative DC did not.

Analysis of partner effects found that husband's supportive DC predicted positively his wife's marital satisfaction. Although his negative DC predicted negatively her marital satisfaction, Cronbach coefficient of his negative DC was low, so interpretation of this data needs to be cautious.

\footnotetext{
${ }^{1}$ Several studies have suggested that coefficients over .10 could be regarded as paired data (e.g., Snijders \& Bosker, 1999). Hence, we treated supportive and negative DC as dyadic data, but the findings should be interpreted with caution.
} 
Table 3. Actor and Partner Effects for Marital Satisfaction in Relation to Dyadic Coping

\begin{tabular}{|c|c|c|c|c|}
\hline & & & $\begin{array}{l}\text { Parameters } \\
\text { Estimate }\end{array}$ & $Z$ \\
\hline \multirow{4}{*}{ Model 1} & \multirow{2}{*}{ Actor effects } & $\mathrm{H}_{\text {Stress Communication }} \rightarrow \mathrm{H}_{\mathrm{MS}}$ & $1.98 * *$ & 3.07 \\
\hline & & $\mathrm{W}_{\text {Stress Communication }} \rightarrow \mathrm{W}_{\mathrm{MS}}$ & $2.73 * * *$ & 4.44 \\
\hline & \multirow{2}{*}{ Partner effects } & $\mathrm{H}_{\text {Stress Communication }} \rightarrow \mathrm{W}_{\mathrm{MS}}$ & -0.54 & -0.70 \\
\hline & & $\mathrm{W}_{\text {Stress Communication }} \rightarrow \mathrm{H}_{\mathrm{MS}}$ & 0.25 & 0.48 \\
\hline \multirow{4}{*}{ Model 2} & \multirow{2}{*}{ Actor effects } & $\mathrm{H}_{\text {Joint DC }} \rightarrow \mathrm{H}_{\mathrm{MS}}$ & $2.27 * * *$ & 3.49 \\
\hline & & $\mathrm{W}_{\text {Joint DC }} \rightarrow \mathrm{W}_{\mathrm{MS}}$ & $1.89 *$ & 2.54 \\
\hline & \multirow{2}{*}{ Partner effects } & $\mathrm{H}_{\text {Joint DC }} \rightarrow \mathrm{W}_{\mathrm{MS}}$ & 0.05 & 0.06 \\
\hline & & $\mathrm{W}_{\text {Joint } \mathrm{DC}} \rightarrow \mathrm{H}_{\mathrm{MS}}$ & -0.66 & -1.17 \\
\hline \multirow{4}{*}{ Model 3} & \multirow{2}{*}{ Actor effects } & $\mathrm{H}_{\text {Supportive DC }} \rightarrow \mathrm{H}_{\mathrm{MS}}$ & $2.52 * * *$ & 4.17 \\
\hline & & $\mathrm{W}_{\text {Supportive DC }} \rightarrow \mathrm{W}_{\mathrm{MS}}$ & 0.28 & 0.39 \\
\hline & \multirow{2}{*}{ Partner effects } & $\mathrm{H}_{\text {Supportive DC }} \rightarrow \mathrm{W}_{\mathrm{MS}}$ & $2.24 * *$ & 2.65 \\
\hline & & $\mathrm{W}_{\text {Supportive DC }} \rightarrow \mathrm{H}_{\mathrm{MS}}$ & -0.51 & -0.99 \\
\hline \multirow{4}{*}{ Model 4} & \multirow{2}{*}{ Actor effects } & $\mathrm{H}_{\text {Negative DC }} \rightarrow \mathrm{H}_{\mathrm{MS}}$ & -0.55 & -1.22 \\
\hline & & $\mathrm{W}_{\text {Negative DC }} \rightarrow \mathrm{W}_{\mathrm{MS}}$ & $-1.41^{*}$ & -1.99 \\
\hline & \multirow{2}{*}{ Partner effects } & $\mathrm{H}_{\text {Negative DC }} \rightarrow \mathrm{W}_{\mathrm{MS}}$ & $-1.53^{* * *}$ & -3.04 \\
\hline & & $\mathrm{W}_{\text {Negative DC }} \rightarrow \mathrm{H}_{\mathrm{MS}}$ & -0.64 & -1.00 \\
\hline \multirow{4}{*}{ Model 5} & \multirow{2}{*}{ Actor effects } & $\mathrm{H}_{\text {Delegated DC }} \rightarrow \mathrm{H}_{\mathrm{MS}}$ & $1.33^{*}$ & 2.17 \\
\hline & & $\mathrm{W}_{\text {Delegated DC }} \rightarrow \mathrm{W}_{\mathrm{MS}}$ & 0.10 & 0.16 \\
\hline & \multirow{2}{*}{ Partner effects } & $\mathrm{H}_{\text {Delegated DC }} \rightarrow \mathrm{W}_{\mathrm{MS}}$ & 1.00 & 1.24 \\
\hline & & $\mathrm{W}_{\text {Delegated DC }} \rightarrow \mathrm{H}_{\mathrm{MS}}$ & -0.11 & -0.23 \\
\hline
\end{tabular}

$N=43$ pairs

Note: $\mathrm{H}=$ husband; $\mathrm{W}=$ wife; $\mathrm{DC}=$ dyadic coping; $\mathrm{MS}=$ Marital Satisfaction ${ }^{\mathrm{a}} n=42$ pairs. $* * *: p<.001$, $* *: p<.01, *: p<.05$,

\section{DISCUSSION}

Actor effects of DCI on marital satisfaction

The present pilot study examined the applicability of DCI in Japanese heterosexual couples. As hypothesized (first hypothesis), Japanese husband (wife)'s positive types of $\mathrm{CC}$ including stress communication and joint DC positively predicted his (her) own marital satisfaction. These findings imply that the DCI can be useful as an index in Japanese 
married couples, like previous European studies (e.g., Bodenmann et al., 2001; Bodenmann \& Shantinath, 2004), although our sample size was limited. Husband's supportive DC and delegated DC positively predicted his own marital satisfaction, whereas wife's supportive DC and delegated DC did not. These findings suggested that Japanese husband's positive CC might be linked with his own marital satisfaction more positively than Japanese wife's positive CC. Previous study suggested that husband's egalitarian attitude was linked with positive CCs and his own marital satisfaction (Mickelson, Claffey, \& Williams, 2006). Actually husband's positive CC had a stronger link with his own marital satisfaction than wife's positive $\mathrm{CC}$ had with her own marital satisfaction, even though the frequency of positive CC did not differ between husband and wife (Bouchard, Sabourin, Lussier, Wright, \& Richer, 1998). Husband's positive CC in our study might play the role of egalitarian attitude which he prefers so his positive $\mathrm{CC}$ might be positively linked with his own marital satisfaction.

The second hypothesis was supported only by wives' DC: wives' negative DC negatively predicted their own marital satisfaction, whereas husbands' negative DC did not. These findings suggested that Japanese wives' negative CC might be linked with their own marital satisfaction more negatively than Japanese husbands' negative CC. Previous study suggested that wife's negative CC was linked with her physical distress (Badr, 2004). Physical distress was linked with negative $\mathrm{CC}$ and low marital quality (Hagedoorn et al., 2000).Wife who expressed negative CC in our study might experience physical distress, which could link negatively with her marital quality.

\section{Partner effects of DCI on marital satisfaction}

We examined the partner effect of DCI on marital satisfaction through APIM, but the partner effects were sparse. Previous study suggested that one's perceived support had more effects on one's own marital satisfaction than spousal actual support did (Reis, Clark, $\&$ Holmes, 2004). Hence, spousal support which is easy to perceive might have more prominent effects than the support which is difficult to perceive. Previous study suggested that woman is sensitive to find social support than man (Flaherty \& Richman, 1989). Furthermore, wife also emphasizes spousal supportive behaviors in her own marital satisfaction more strongly than husband does (Acitelli \& Antonucci, 1994). These findings imply that husband's positive and negative CC might be easy to find from wife 's perspective and be linked with her marital satisfaction. Actually husbands' negative DC and supportive DC in our sample had negative and positive links with their wives' marital satisfaction respectively, whereas wives' negative DC and supportive DC did not.

Our study had five limitations. First, the number of couples was limited, so the findings cannot be regarded as conclusive. Second, couples' employment status and educational level was not clear. This might have affected their CC (e.g., Berg \& Upchurch, 2007; Crossfield et al., 2005). Third, the age of their children was not measured, and differences here can affect the volume of household chores (e.g., Sagara, Ito, \& Ikeda, 2008) and distress within couple. Fourth, our sampling may select only satisfied couples. Fifth, the crosssectional design did not allow empirical examination of the causal links between CC and marital relationships (e.g., Bodenmann et al., 2001; Bodenmann \& Shantinath, 2004). 
Despite these limitations, our pilot study examined the applicability of the DCI in Japanese married couples. Addition of Japanese married couples on previous European and American findings (Berg \& Upchurch, 2007; Bodenmann, 2005; Lyons et al., 1998) could enhance the generalizability of CC. Furthermore, comparison of our data with previous findings could clarify cultural differences. Actually, our study, Kawashima et al. (2014) and $\mathrm{Xu}$ et al. (in press) disconfirmed the concept of delegated coping in Asian population. These findings could indicate conceptual revision of delegated coping and could contribute theoretical development of CC. Through the process of adding culturally minor but divergent data, study of CC could be more broaden and generalizable.

\section{REFERENCES}

Acitelli, L. K., \& Antonucci, T. C. 1994. Gender differences in the link between marital support and satisfaction in older couples. Journal of Personality and Social Psychology, 67, 688-698. doi:10.1037/00223514.67.4.688

Badr, H. 2004. Coping in marital dyads: A contextual perspective on the role of gender and health. Personal Relationships, 11, 197-211. doi:10.1111/j.1475-6811.2004.00078.x

Berg, C. A., \& Upchurch, R. 2007. A developmental-contextual model of couples coping with chronic illness across the adult life span. Psychological Bulletin, 133, 920-954. doi:10.1037/0033-2909.133.6.920

Bodenmann, G. 1995. A systemic-transactional conceptualization of stress and coping in couples. Swiss Journal of Psychology, 54, 1, 34-49.

Bodenmann, G. 2005. Dyadic coping and its significance for marital functioning. In T. A. Revenson, K. Kayser, \& G. Bodenmann (Eds.), Couples coping with stress: Emerging perspectives on dyadic coping (pp. 33-49). Washington, DC: American Psychological Association. doi:10.1037/11031-002

Bodenmann, G. 2008. Dyadisches coping inventar: Testmanual [Dyadic coping inventory: Test manual]. Bern, Switzerland: Huber.

Bodenmann, G., Charvoz, L., Cina, A., \& Widmer, K. 2001. Prevention of marital distress by enhancing the coping skills of couples: 1-year follow-up-study. Swiss Journal of Psychology, 60, 3-10. doi:10.1024//1421-0185.60.1.3

Bodenmann, G., Pihet, S., \& Kayser, K. 2006. The relationship between dyadic coping and marital quality: A 2-year longitudinal study. Journal of Family Psychology, 20, 485-493. doi:10.1037/0893-3200.20.3.485

Bodenmann, G., \& Shantinath, S. D. 2004. The Couples Coping Enhancement Training (CCET): A new approach to prevention of marital distress based upon stress and coping. Family Relations, 53, 477484. doi:10.1111/j.0197-6664.2004.00056.x

Bouchard, G., Sabourin, S., Lussier, Y., Wright, J., \& Richer, C. 1998. Predictive validity of coping strategies on marital satisfaction: Cross-sectional and longitudinal evidence. Journal of Family Psychology, 12, 112-131. doi:10.1037/0893-3200.12.1.112

Cook, W. L., \& Kenny, D. A. 2005. The actor-partner interdependence model: A model of bidirectional effects in developmental studies. International Journal of Behavioral Development, 29, 101-109. doi: 10.1080/01650250444000405

Coyne, J. C., \& Smith, D. A. 1991. Couples coping with a myocardial infarction: A contextual perspective on wives' distress. Journal of Personality and Social Psychology, 61, 404-412. doi:10.1037/00223514.61.3.404

Crossfield, S., Kinman, G., \& Jones, F. 2005. Crossover of occupational stress in dual-career couples: The role of work demands and supports, job commitment and marital communication. Community, Work \& Family, 8, 211-232. doi:10.1080/13668800500049779

Ditzen, B., Neumann, I. D., Bodenmann, G., von Dawans, B., Turner, R. A., Ehlert, U., \& Heinrichs, M. 2007. Effects of different kinds of couple interaction on cortisol and heart rate responses to stress in women. Psychoneuroendocrinology, 32, 565-574. doi:10.1016/j.psyneuen.2007.03.011

Falconier, M. K. 2013. Traditional gender role orientation and dyadic coping in immigrant Latino couples: 
Effects on couple functioning. Family Relations, 62, 269-283. doi:10.1111/fare.12002

Flaherty, J., \& Richman, J. 1989. Gender differences in the perception and utilization of social support: Theoretical perspectives and an empirical test. Social Science \& Medicine, 28, 1221-1228. doi:10.1016/0277-9536(89)90340-7

Hagedoorn, M., Kuijer, R. G., Buunk, B. P., DeJong, G. M., Wobbes, T., \& Sanderman, R. 2000. Marital satisfaction in patients with cancer: Does support from intimate partners benefit those who need it most?. Health Psychology, 19, 274-282. doi:10.1037/0278-6133.19.3.274

Kawashima, A., Yoshitake, N., Matsumoto, S., \& Sugawara, M. 2014, September. Fuufu ko-ping no kentou: Kodomono fuufukan kattoujino jyoutyoannteisei ni tyakumokusite [Examining dyadic coping: Focusing on children's emotional security during parents' marital conflicts]. Poster session presented at Japanese Society of Child Science, Tokyo, Japan.

Kenny, D. A., Kashy, D., \& Bolger, N. 1998. Data analysis in social psychology. In D. Gilbert, S. Fiske, \& G. Lindzey (Eds.), Handbook of social psychology (4th ed., pp. 233-265). New York, NY: McGrawHill.

Lazarus, R. S., \& Folkman, S. 1984. Stress, appraisal, and coping. New York, NY: Springer.

Ledermann, T., Bodenmann, G., Gagliardi, S., Charvoz, L., Verardi, S., Rossier, J., . . . Iafrate, R. 2010. Psychometrics of the Dyadic Coping Inventory in three language groups. Swiss Journal of Psychology, 69, 201-212. doi:10.1024/1421-0185/a000024

Li, P.-F., \& Wickrama, K. A. S. 2014. Stressful life events, marital satisfaction, and marital management skills of Taiwanese couples. Family Relations, 63, 193-205. doi:10.1111/fare.12066

Lyons, R. F., Mickelson, K. D., Sullivan, M. J., \& Coyne, J. C. 1998. Coping as a communal process. Journal of Social and Personal Relationships, 15, 579-605. doi:10.1177/0265407598155001

Mickelson, K. D., Claffey, S. T., \& Williams, S. L. 2006. The moderating role of gender and gender role attitudes on the link between spousal support and marital quality. Sex Roles, 55, 73-82. doi:10.1007/ s11199-006-9061-8

Reis, H. T., Clark, M. S., \& Holmes, J. G. 2004. Perceived partner responsiveness as an organizing construct in the study of intimacy and closeness. In D. J. Mashek \& A. Aron (Eds.), Handbook of closeness and intimacy (pp. 201-225). Mahwah, NJ: Erlbaum.

Sagara, J., Ito, Y., Ikeda, M. 2008. Fuufu no kekkonmanzokudo to kaji-ikuji buntann ni okeru riso to genjitsu no zure [Relationship between marital satisfaction of married couples, and discrepancies between ideals and realities of sharing of housework and child-raising]. Japanese Journal of Family Psychology, 22, 119-128. (In Japanese)

Schumm, W. R., Paff-Bergen, L. A., Hatch, R. C., Obiorah, F. C., Copeland, J. M., Meens, L. D., \& Bugaighis, M. A. 1986. Concurrent and discriminant validity of the Kansas Marital Satisfaction Scale. Journal of Marriage and Family, 48, 381-387. doi:10.2307/352405.

Shimizu, H. 2016. An introduction to the statistical free software HAD: Suggestions to improve teaching, learning and practice data analysis. Journal of Media, Information and Communication, 1, 59-73. (In Japanese with English abstract)

Snijders, T., \& Bosker, R. 1999. Multilevel analysis: An introduction to basic and advanced multilevel modeling. London, United Kingdom: Sage.

Sugawara, M., \& Takuma, N. 1997. Fuufukan no sinmitsusei no hyoka: Jikinyuushiki fuufukannkeisyakudo ni tsuite [Assessment of marital intimacy: A review of self-rating scales]. Archives of Psychiatric Diagnostics and Clinical Evaluation, 8, 155-166. (In Japanese)

Vedes, A., Nussbeck, F. W., Bodenmann, G., Lind, W., \& Ferreira, A. 2013. Psychometric properties and validity of the Dyadic Coping Inventory in Portuguese. Swiss Journal of Psychology, 72, 149-157. doi:10.1024/1421-0185/a000108

Xu, F., Hilpert, P., Randall, A. K., Li, Q., \& Bodenmann, G. in press. Validation of the Dyadic Coping Inventory with Chinese couples: Factorial structure, measurement invariance, and construct validity. Psychological Assessment. doi:10.1037/pas0000329 